\title{
Dermoscopic rainbow pattern: A strong clue to malignancy or just a light show?
}

\author{
(D) Omer Faruk Elmas, ${ }^{1}$ (i) Herman Mayisoglu, ${ }^{2}$ (D) Murat Celik, ${ }^{3}$ (i) Asuman Kilitci, $^{4}$ (i) Necmettin Akdeniz ${ }^{5}$ \\ ${ }^{1}$ Department of Dermatology and Veneorology, Ahi Evran University Faculty of Medicine, Kirsehir, Turkey \\ ${ }^{2}$ Department of Dermatology and Veneorology, Medicana Hospital, Istanbul, Turkey \\ ${ }^{3}$ Department of Pathology, Kars State Hospital, Kars, Turkey \\ ${ }^{4}$ Department of Pathology, Ahi Evran University Faculty of Medicine, Kirsehir, Turkey \\ ${ }^{5}$ Department of Dermatology and Veneorology, Istanbul Medeniyet University Faculty of Medicine, Istanbul, Turkey
}

\begin{abstract}
OBJECTIVE: Rainbow pattern is a dermoscopic finding composed of multiple colors simulating a rainbow. It is known as a characteristic feature of Kaposi's sarcoma. Here, we reported different non-Kaposi's sarcoma conditions with a rainbow pattern aiming to discuss the diagnostic significance of the finding.

METHODS: In this multicenter study, dermoscopic images of the non-Kaposi's sarcoma lesions having a histopathological diagnosis were reviewed for the presence of a rainbow pattern. Dermoscopic examination was performed by a polarized handheld dermoscope with $\times 10$ magnification.

RESULTS: A total of 840 lesions were reviewed and 21 (2\%) non-Kaposi sarcoma lesions having dermoscopic rainbow pattern were detected. These lesions were as follows; pyogenic granuloma $(n=4,19 \%)$, hypertrophic scar $(n=4,19 \%)$, basal cell carcinoma $(n=2,10 \%)$, dermatofibroma $(n=2,10 \%)$, angiokeratoma $(n=2,10 \%)$, blue nevus $(n=1,5 \%)$, granuloma annulare $(n=1,5 \%)$, strawberry angioma $(n=1,5 \%)$, epidermal cyst $(n=1,5 \%)$, malignant melanoma $(n=1,5 \%)$, dissecting cellulitis $(n=1,5 \%)$ and subungual hematoma $(n=1,5 \%)$. The most common localization was limb $(n=14,67 \%)$ followed by face $(n=3,14 \%)$.
\end{abstract}

CONCLUSION: We suggest that the rainbow pattern is a complex and quite unspecific optic phenomenon which can be seen both in vascular and non-vascular lesions. Its diagnostic significance should be considered in the context of the other structural dermoscopic finding. To the best of our knowledge, to our knowledge, this is the most comprehensive study focusing on rainbow pattern in non-Kaposi's sarcoma lesions. Here, we also reported rainbow pattern in dissecting cellulitis, granuloma annulare and subungual hematoma which has not been shown to have rainbow pattern previously.

Keywords: Dermoscopy; Kaposi's sarcoma; optic phenomenon; rainbow pattern.

Cite this article as: Elmas OF, Mayisoglu H, Celik M, Kilitci A, Akdeniz N. Dermoscopic rainbow pattern: A strong clue to malignancy or just a light show? North Clin Istanb 2020;7(5):494-498.

$\mathrm{R}$ ainbow pattern (RP) is first described by Hu et al. as a multicolored dermoscopic finding composed of multiple colors simulating a rainbow which does not have a peculiar histopathogical correlation $[1,2]$. Initially, the pattern was considered as a highly specific dermoscopic

clue to Kaposi's sarcoma [3]. Recently, however, diagnostic significance of RP has been a subject of debate $[4,5]$. Current literature reported RP in many different conditions, including lichen planus, melanoma, dermatofibroma, angiokeratoma, blue nevus, scars, acroangiodermatitis and 

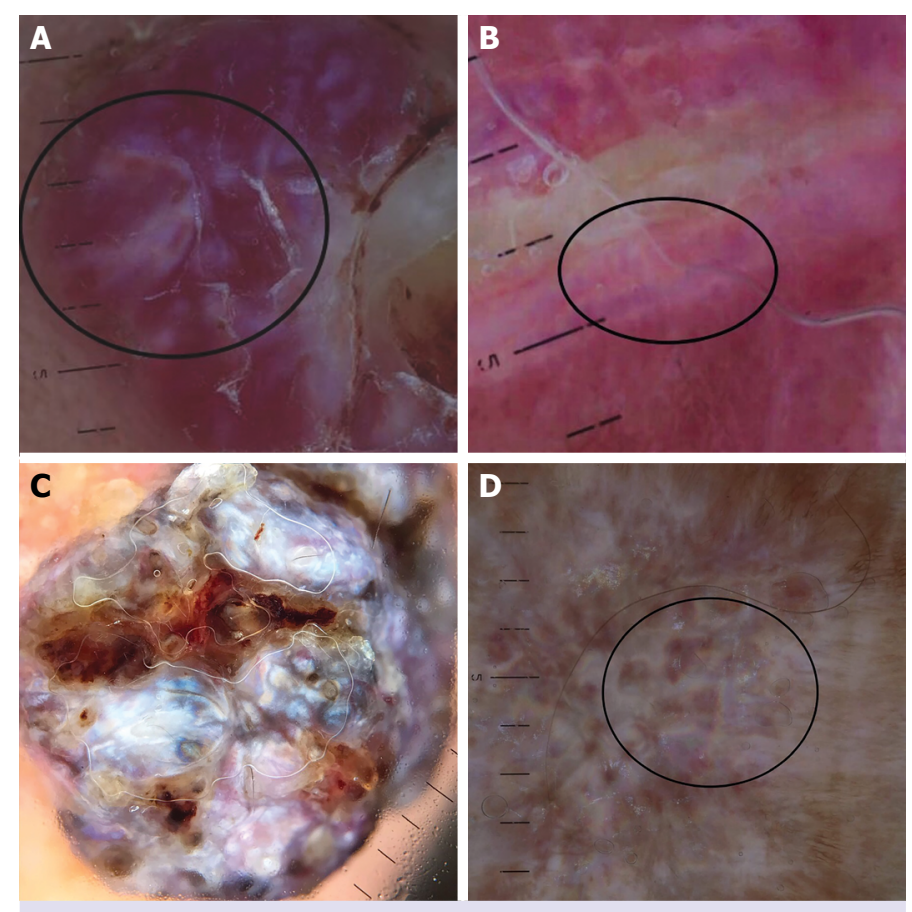

FIGURE 1. Dermoscopic rainbow pattern in pyogenic granuloma (A), hypertrophic scar (B), basal cell carcinoma (C) and dermatofibroma (D).

stasis dermatitis $[1,4,5]$. In this study, we also reported different non-Kaposi's sarcoma conditions with RP aiming to discuss diagnostic significance of the finding.

\section{MATERIALS AND METHODS}

In this multicenter study, dermoscopic images of the lesions having a histopathological diagnosis were reviewed retrospectively for presence of RP. The lesions were collected from outpatient clinics of three centers between June 2016 and January 2019. Dermoscopic examination was performed by a polarized handheld dermoscope with $x 10$ magnification (Dermlite 4, 3GEN Inc, San Juan Capistrano, CA, USA). Capture of dermoscopic images was done using a high-resolution mobile camera phone attached to the dermoscope (iPhone 7 plus, Apple Inc, CA, USA). An additional $\mathrm{x} 2$ digital zoom was used to achieve a total of $\mathrm{x} 20$ magnification. All the procedures followed were in accordance with the Helsinki Declaration and this study was approved by the local clinical research ethics committee (Ethical clearance number and date: 2019-01/09, 08,01.2019).

\section{Statistical Analysis}

SPSS Windows version 24.0 package software (SPSS Inc., Chicago, IL, USA) was used for descriptive statistical analysis.
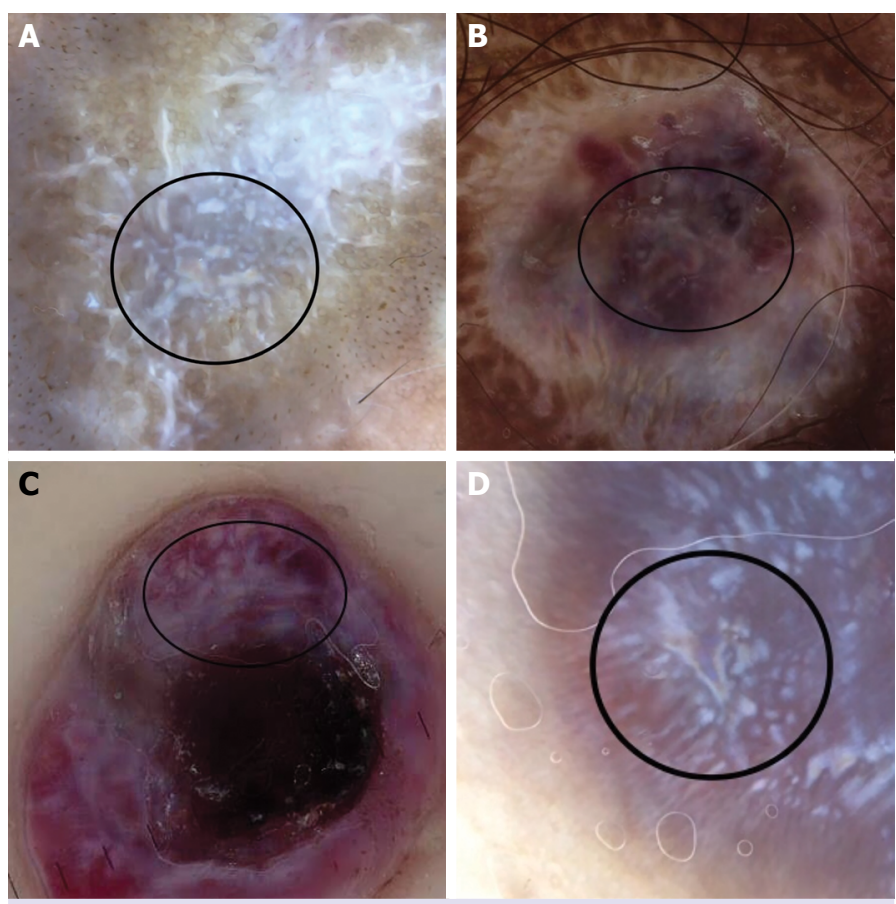

FIGURE 2. Dermoscopic rainbow pattern in dermatofibroma (A), angiokeratoma (B), angiokeratoma (C) and blue nevus (D).

\section{RESULTS}

In this study, 840 lesions, including nevi, benign and malignant adnexal tumors, vascular lesions, basal cell carcinomas, squamous cell carcinomas, melanomas, epidermal cysts, subungual and subcorneal hematomas, and scars, were retrospectively reviewed. We detected a total of 21 non-Kaposi sarcoma lesions having dermoscopic RP. These lesions were as follows: pyogenic granuloma $(n=4,19 \%)$ (Fig. 1A), hypertrophic scar $(n=4,19 \%)$ (Fig. 1B), basal cell carcinoma $(n=2,10 \%)$ (Fig. 1C), dermatofibroma $(n=2,10 \%)$ (Fig. 1D, Fig. 2A), angiokeratoma ( $\mathrm{n}=2,10 \%)$ (Fig. 2B, C), blue nevus $(n=1,5 \%)$ (Fig. $2 D)$, granuloma annulare $(n=1$, 5\%) (Fig. 3a), strawberry angioma $(n=1,5 \%)$ (Fig. 3Bb), epidermal cyst $(n=1,5 \%)$, malignant melanoma $(n=1$, 5\%) (Fig. 3C), dissecting cellulitis and subungual hematoma $(n=1,5 \%)$ (Fig. 3D). The mean age of the patient was 48 years. The majority of the participants in this study was male (62\%). The most common localization was limb $(n=14,67 \%)$ followed by face $(n=3,14 \%)$.

The demographic parameters and dermoscopic features of the lesions have been shown in Table 1 .

\section{DISCUSSION}

$\mathrm{RP}$ was previously thought to be related with distinctive 

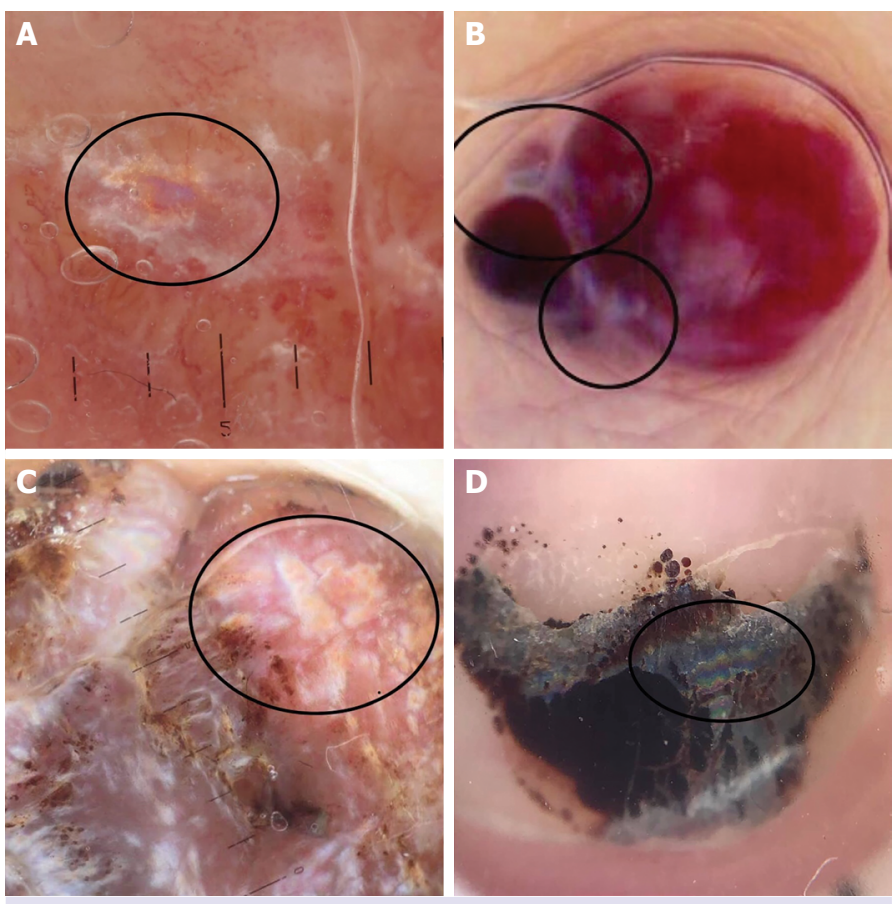

FIGURE 3. Dermoscopic rainbow pattern in granuloma annulare (A), strawberry angioma (B), malignant melanoma (C) and subungual hematoma (D).

microscopic vascular structures. This hypothesis may explain RP observed in vascular lesions like Kaposi's sarcoma and pyogenic granuloma; however, it fails to explain presence of RP in non-vascular lesions. Recently, RP has been considered as a more complex optic phenomenon. It has been suggested that polarized light interacts with not only vascular structures but also different parts of skin structures as it passes through skin [5].

When reviewing the literature, there are few studies focusing on the RP in non-Kaposi's sarcoma lesions and all of them are case reports or case series, including few numbers of patient. Cheng et al. [3] claimed that RP is highly specific to Kaposi's sarcoma. They suggested that the light beam is diffracted in the dermis and this may be the possible mechanism of RP. Then, Vázquez-López et al. [5] pointed out the term "dichroism" which suggested a more complex interaction with polarized lights. According to this hypothesis, light in different status of polarization is absorbed in different amounts as it penetrates into an object. Heterogenous and layered nature of dermis determine the absorbance and retardance of polarized light resulting a spectrum of colors. A fluid application (e.g., immersion oil and isopropyle alcohol) may also enhance the effects of the polarized light. We observed the application of isopropyl alcohol enhances the appearance of RP. However, RP has not been detected in any case on non-polarized dermoscopy with or without fluid.

Satta et al. [6] claimed that RP is only seen in raised lesions of Kaposi's sarcoma and is totally absent in macular stage of the disease. They suggested that spindle cell proliferation arranged as bundles around vascular structures in varying size and shape cause $\mathrm{RP}$ in nodular $\mathrm{Ka}$ posi's sarcoma.

In the present study, 24\% $(n=5)$ percent of the lesions showing RP were vascular proliferations, including pyogenic granuloma, strawberry angioma, angiokeratoma and, most of the lesions $(n=17,81 \%)$ showed dermoscopic and histopathological evidence of increased superficial dermal vascularity. Pyogenic granuloma and nodular Kaposi's sarcoma may demonstrate similar clinical and dermoscopic findings [7, 8]. Given the non-specific nature of RP, other dermoscopic clues should be considered in the differential diagnosis between the two entity. In a recent study, we concluded that the presence of reddish structureless areas along with intersecting thick white lines is a strong dermoscopic clue to PG [8].

The site of the lesion may also contribute to RP. In the study of Kelati et al. [4], almost all the lesions were located to the limbs. In the present study, 67 percent of the lesions were also located to the limbs. Peculiar vasculature of the limbs may be an additional factor for RP formation.

Pyogenic granuloma, angiokeratoma, scars, melanoma, basal cell carcinoma, dermatofibroma, blue nevus and Merkel cell carcinoma were previously reported to show RP [1, 4, 5, 9-11]. To our knowledge, RP has not been described for granuloma annulare, dissecting cellulitis and subungual hematoma previously. It was remarkable that, both dermoscopy and histopathology of the granuloma annulare case showed prominent superficial vascular structures. Dermoscopy of the subungual hematoma showed different color and shades of blood which may correspond RP.

In this study, overwhelming majority of the lesions was benign and just three lesions (two basal cell carcinomas and one melanoma) were malignant. In this context, $\mathrm{RP}$ cannot be considered as a clue to malignancy alone. Exceptionally, high incidence of RP in Kaposi's sarcoma should be noted.

It can be concluded that vascular structures are more tend to interact with polarized light and this explains the frequency of RP in vascular lesions; however, non-vascular elements of the skin may also have an interaction with polarized light resulting RP. In the present study, 19 
TABLE 1. The demographic parameters and dermoscopic features of the lesions

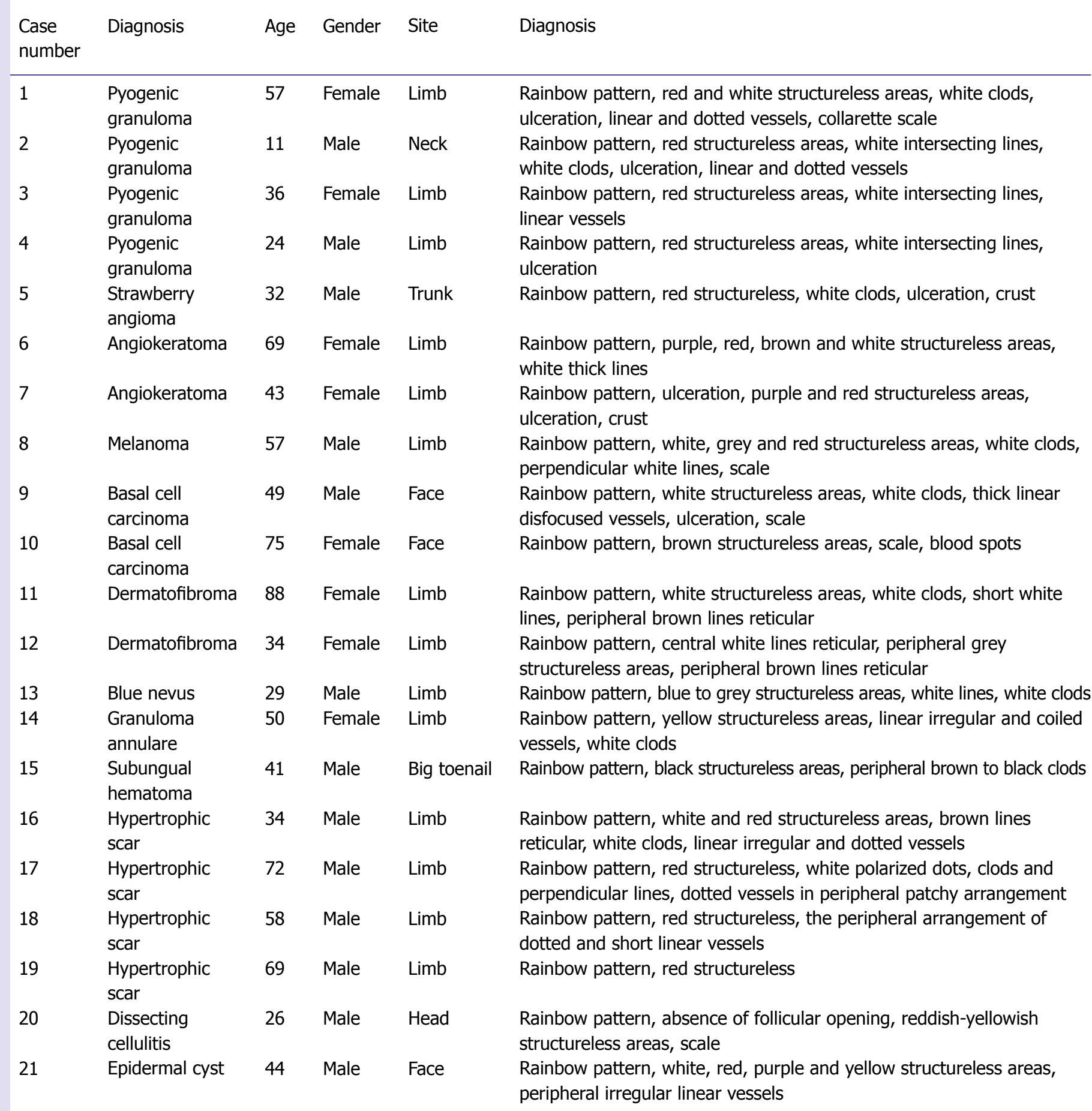

percent of the lesion did not show any dermoscopic or histopathological evidence of increased vascularity.

We agree that RP is a complex and quite nonspecific optic phenomenon which can be seen both in vascular and non-vascular lesions and it cannot be considered as a specific clue to Kaposi sarcoma. Its diagnostic significance should be considered in the context of the other structural dermoscopic finding. To our knowledge, this is the most comprehensive study focusing on RP in non-Kaposi's sarcoma lesions. 
Ethics Committee Approval: All the procedures followed were in accordance with the Helsinki Declaration and this study was approved by the local clinical research ethics committee (date: 08.01.2019, number: 2019-01/09).

Conflict of Interest: No conflict of interest was declared by the authors.

Financial Disclosure: The authors declared that this study has received no financial support.

Authorship Contributions: Concept - OFE, NA, HM; Design OFE, HM, MC; Supervision - OFE, NA, AK; Materials - MC, AK, OFE; Data collection and/or processing - OFE, HM; Analysis and/or interpretation - MC, NA, HM; Literature review - OFE, AK; Writing - OFE, HM, MC, AK, NA; Critical review - OFE, HM, MC, AK, NA.

\section{REFERENCES}

1. Uzunçakmak TK, Ozkanli S, Karadağ AS. Dermoscopic rainbow pattern in blue nevus. Dermatol Pract Concept 2017;7:60-2. [CrossRef]

2. Hu SC, Ke CL, Lee CH, Wu CS, Chen GS, Cheng ST. Dermoscopy of Kaposi's sarcoma: areas exhibiting the multicoloured 'rainbow pattern'.J Eur Acad Dermatol Venereol 2009;23:1128-132. [CrossRef]
3. Cheng ST, Ke CL, Lee CH, Wu CS, Chen GS, Hu SC. Rainbow pattern in Kaposi's sarcoma under polarized dermoscopy: a dermoscopic pathological study. Br J Dermatol 2009;160:801-9. [CrossRef]

4. Kelati A, Mernissi FZ. The rainbow pattern in dermoscopy: A zoom on nonkaposi sarcoma skin diseases. Biomed J 2018;41:209-10. [CrossRef]

5. Vázquez-López F, García-García B, Rajadhyaksha M, Marghoob AA. Dermoscopic rainbow pattern in non-Kaposi sarcoma lesions. Br J Dermatol 2009;161:474-5. [CrossRef]

6. Satta R, Fresi L, Cottoni F. Dermoscopic rainbow pattern in Kaposi's sarcoma lesions: our experience. Arch Dermatol 2012;148:1207-8.

7. Kizilyel O, Metin M, Elmas Ö, Bilen H, Akdeniz N, Atasoy M, et al. Pyogenic granuloma-like Kaposi sar-coma: Report of two cases. Cumhuriyet Tip Dergisi 2015;37:152-5. [CrossRef]

8. Elmas ÖF, Akdeniz N, Acar EM, Kilitçi A. Pyogenic granuloma and nodular Kaposi's sarcoma: dermoscopic clues for the differential diagnosis. Turk J Med Sci 2019;49:1471-8. [CrossRef]

9. Di Meo N, Corneli P, Magaton Rizzi G, Zalaudek I. Basal cell carcinoma under the rainbow. G Ital Dermatol Venereol 2020;155:244-5.

10. di Meo N, Vernoni S, Longone M, Trevisan G. Image Galleryः Merkel cell carcinoma under the rainbow. Br J Dermatol 2017;177:e166. [CrossRef]

11. Pinos León VH, Granizo Rubio JD. Acral pseudolymphomatous angiokeratoma of children with rainbow pattern: A mimicker of Kaposi sarcoma. J Am Acad Dermatol 2017;76:S25-7. [CrossRef] 